Johnson \& Wales University ScholarsArchive@JWU

Health \& Wellness Department Faculty

Publications and Research

College of Health \& Wellness

2015

\title{
Cigarette smoking and emergency care utilization among asthmatic adults in the 2011 Asthma Callback Survey
}

Sophie A. Khokhawalla

Brown University

Samantha R. Rosenthal

Johnson \& Wales University - Providence, Samantha.Rosenthal@jwu.edu

Deborah N. Pearlman

Brown University

Elizabeth W. Triche

Brown University

Follow this and additional works at: https://scholarsarchive.jwu.edu/health_fac

Part of the Medicine and Health Sciences Commons

\section{Repository Citation}

Khokhawalla, Sophie A.; Rosenthal, Samantha R.; Pearlman, Deborah N.; and Triche, Elizabeth W., "Cigarette smoking and emergency care utilization among asthmatic adults in the 2011 Asthma Callback Survey" (2015). Health \& Wellness Department Faculty Publications and Research. 14.

https://scholarsarchive.jwu.edu/health_fac/14

This Article is brought to you for free and open access by the College of Health \& Wellness at ScholarsArchive@JWU. It has been accepted for inclusion in Health \& Wellness Department Faculty Publications and Research by an authorized administrator of ScholarsArchive@JWU. For more information, please contact jcastel@jwu.edu. 


\section{Journal of Asthma}

\section{Cigarette smoking and emergency care utilization among asthmatic adults in the 2011 Asthma Call- back Survey}

Sophie A. Khokhawalla MPH, Samantha R. Rosenthal PhD, MPH, Deborah N. Pearlman PhD \& Elizabeth W. Triche PhD

To cite this article: Sophie A. Khokhawalla MPH, Samantha R. Rosenthal PhD, MPH, Deborah N. Pearlman PhD \& Elizabeth W. Triche PhD (2015) Cigarette smoking and emergency care utilization among asthmatic adults in the 2011 Asthma Call-back Survey, Journal of Asthma, 52:7, 732-739, DOI: 10.3109/02770903.2015.1004337

To link to this article: http://dx.doi.org/10.3109/02770903.2015.1004337

Accepted author version posted online: 07 Jan 2015.

Published online: 17 Apr 2015.

Submit your article to this journal $₫$

Џ Article views: 91

Q View related articles $\sqsubset$

View Crossmark data $\nearrow$ 


\title{
Cigarette smoking and emergency care utilization among asthmatic adults in the 2011 Asthma Call-back Survey
}

\author{
Sophie A. Khokhawalla, $\mathrm{MPH}^{1}$, Samantha R. Rosenthal, PhD, $\mathrm{MPH}^{2}$, Deborah N. Pearlman, $\mathrm{PhD}^{2}$, and \\ Elizabeth W. Triche, $\mathrm{PhD}^{2}$ \\ ${ }^{1}$ Masters Program in Public Health and ${ }^{2}$ Department of Epidemiology, Brown University School of Public Health, Providence, RI, USA
}

\begin{abstract}
Objective: Estimate the association between smoking and emergency care in the past 12 months among asthmatic adults in a nationally representative sample. Methods: Using the 2011 Asthma Call-Back Survey, the association between smoking status and emergency department (ED) and urgent visits among asthmatic adults $(n=12339)$ was assessed through multivariable logistic regression by a cross-sectional study design. Analyses used survey weights for US population-based estimates. Attributable and population attributable risk were calculated to describe the potential benefits of smoking cessation. Results: Adjusting for potential confounders, during the past 12 months former smokers had 1.30 ( $95 \% \mathrm{Cl}: 0.97,1.74)$ times the odds and current smokers had $1.46(95 \% \mathrm{Cl}: 1.05,2.03)$ times the odds of visiting the ED compared to never smokers. Former smokers had 1.28 (95\% Cl: $0.99,1.65)$ times the odds and current smokers had 1.29 ( $95 \% \mathrm{Cl}: 0.96,1.73)$ times the odds of urgent visits compared to never smokers. Among adult asthmatics, an estimated $9 \%$ of ED visits and $6 \%$ of urgent visits can be attributed to current smoking while $7 \%$ of ED visits and $7 \%$ of urgent visits can be attributed to former smoking. Conclusions: Current and former smokers are more likely to need emergency care than never smokers. About $10 \%$ of emergency care visits among asthmatics can be attributed to smoking assuming smoking is causally related to emergency care. Long-term effective management of asthma, particularly the prevention and cessation of smoking, could reduce emergency care use and health care costs.
\end{abstract}

\author{
Keywords \\ Emergency department, healthcare costs, \\ tobacco use, uncontrolled asthma, \\ urgent care
}

History

Received 27 August 2014

Revised 14 November 2014

Accepted 1 January 2015

Published online 17 April 2015

\section{Introduction}

Tobacco use, a dominant risk factor for mortality and the leading preventable cause of death, has resulted in greater than 20 million premature deaths since the initial Surgeon General's Report in 1964. The prevalence of current cigarette smoking among US adults is $18 \%$, with high economic costs attributable to treating tobacco-related diseases, loss in productivity as a result of premature death and public health costs from secondhand smoke exposure [1]. Tobacco use is responsible for approximately $5 \%$ of adult ED visits, $7 \%$ of admissions to the hospital and $10 \%$ of charges from the hospital [2].

Cigarette smoking has also been recognized as the most important risk factor for the development of acute and chronic respiratory illness, acute exacerbations of respiratory illness and related morbidity and mortality [3]. Silverman et al. found that cigarette smoking was common among asthmatic adults who visited the ED with 35\% of patients ages 18 and 54 years comprising current smokers and 23\% classified as

Correspondence: Sophie A. Khokhawalla, MPH, Masters Program in Public Health, Brown University School of Public Health, 121 South Main Street, Providence, RI 02912, USA. Tel: +1 954 261-7286. E-mail: sophie_khokhawalla@alumni.brown.edu former smokers [4]. Smoking exacerbates chronic asthma, decreases lung function and weakens short-term therapeutic responses to corticosteroids [5,6]. In fact, among acute asthmatics current and past smoking were related to a higher risk of ED visits, and when compared to never smokers, current smokers were prospectively associated with a greater risk of hospitalization and hospital-based care for asthma $[7,8]$.

ED visits are particularly expensive, increasing rapidly (e.g. a 77\% increase from 2000 to 2010) and representing about $4 \%$ of health care costs in the US [9]. In 2009, there were roughly 2 million adult asthma-related ED visits and 480000 asthma-related hospitalizations, resulting in approximately $\$ 56$ billion in healthcare costs [10-12]. Asthmatic adults who depend on ED services are generally considered to have substandard asthma control and poor prognosis [13]. Lenhardt et al. revealed that asthmatic adults who visited the ED for their condition had a large burden of disease in the month preceding their ED visit and the month following their visit. Furthermore, these asthmatic adults demonstrated low asthma-specific and general quality-of-life scores post-ED visit [14]. Additional costs to the healthcare system among asthmatics arise from physician visits. In 2009, asthmatic patients had 8.9 million physician visits, many of which were 
likely due to needs for urgent visits [15]. The overall estimated annual cost for patients with difficult-to-control asthma is more than $\$ 2500$ per patient as opposed to an average annual cost of $\$ 1238$ per asthmatic patient [7].

The purpose of this study is to estimate nationally the extent to which smoking contributes to the use of emergency care for asthma in a nationally representative sample using the Asthma Call-Back Survey (ACBS). In addition, we calculated attributable and population attributable risk to describe the potential benefits of smoking cessation in this population.

\section{Methods}

\section{Survey data description}

The Behavioral Risk Factor Surveillance System (BRFSS) is a national, cross-sectional, state-based, random-digit dialed telephone survey conducted by state health departments and developed by the Centers for Disease Control and Prevention (CDC). The BRFSS uses a disproportionate, stratified sampling plan and includes an iterative proportional fitting weighting method to adjust for the under-represented groups in the sample and more accurately portray a nationally representative sample [16]. The 2011 BRFSS survey included 506467 individuals in their monthly landline telephone interviews and obtained information on state-specific data on preventative health practices and health risk behaviors related to chronic disease and injury from a random sample of adults, one per household, using a standardized questionnaire $[17,18]$. Adults 18 years or older who live in households are asked to participate in this survey comprised of core questions that were asked by all states and optional modules that each state selected to use on their questionnaire [16].

Two weeks after the annual BRFSS survey was conducted, a follow-up ACBS was administered to participants who responded "yes" to the BRFSS question "have you ever been told by a doctor, nurse or other health professional that you had asthma?"' The ACBS record for a respondent includes the entire BRFSS interview record followed by the ACBS data. From the parent survey (BRFSS), the ACBS inherits the complex sampling design. The BRFSS includes a question on smoking status. The linked adult ACBS provides information about adults with asthma, including demographics, symptoms, asthma self-management practices, healthcare utilization and associated costs [19]. In the 2011 ACBS, 41 states participated and there were a total of 16693 participants who completed the ACBS survey. The 2011 BRFSS landline interview median response rate was 52.9\% and the 2011 ACBS median response rate was $93.1 \%$ [20,21]. Response rates for both surveys were calculated using standards set by the American Association of Public Opinion Research Response Rate Formula \#4 [22]. The weighting scheme for both surveys accounts for the non-coverage bias.

\section{Analytic sample}

The 2011 ACBS dataset consists of a total of 16693 initial observations [23]. However, only current asthmatic adults, defined as those who responded "yes" to the question "do you still have asthma?" with valid values for smoking status,

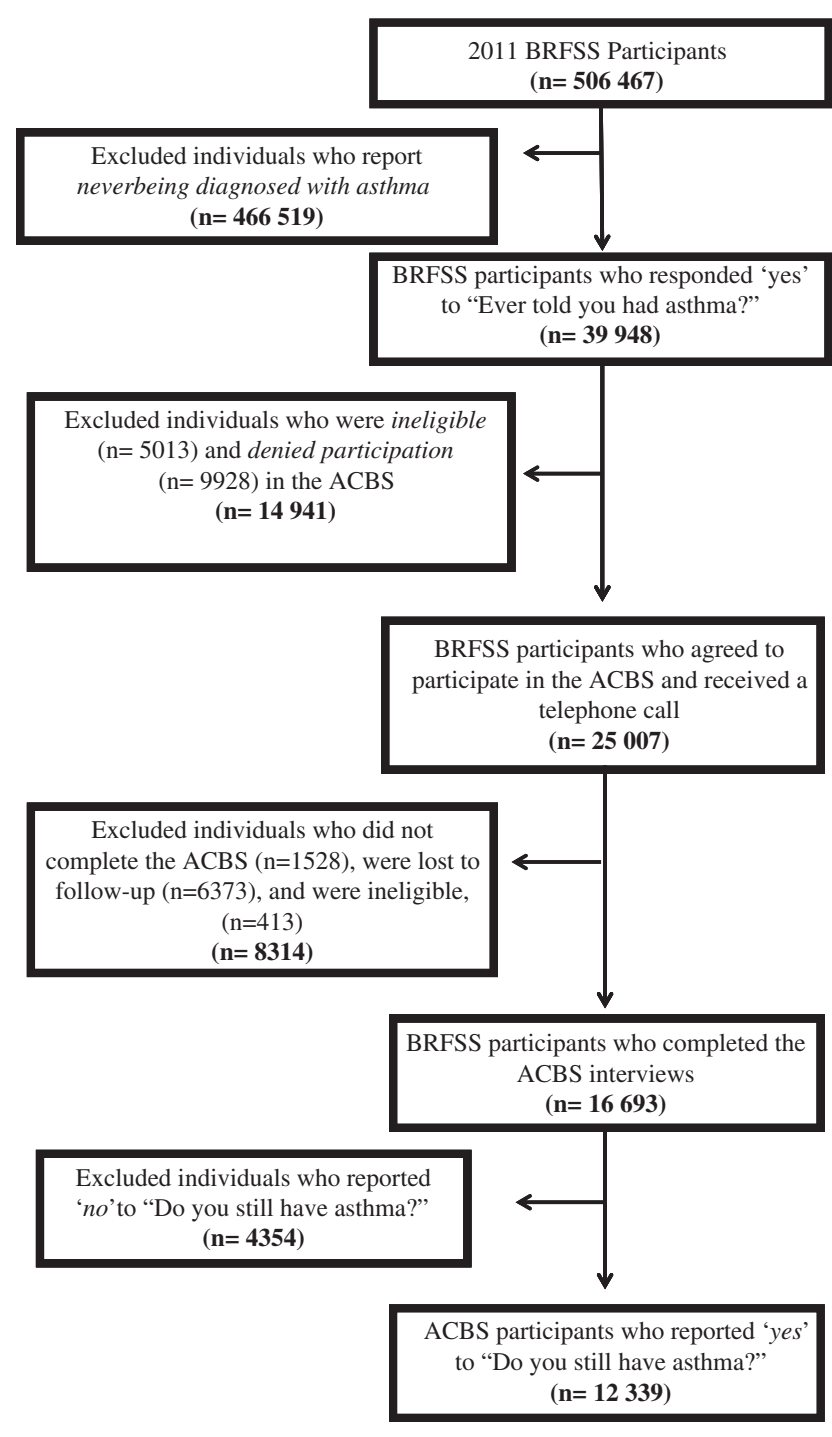

Figure 1. Schema of analytic sample.

were included in the final analytic sample $(n=12339$ respondents; Figure 1).

\section{Assessment of dependent variables}

Emergency care included ED visits and urgent treatment visits. Having ED visits was operationalized using the question "during the past 12 months, how many times did you visit an emergency room or urgent care center because of your asthma?" The number of ED visits was categorized into a binary, mutually exclusive, variable labeled as "no visits" and "any visits". Having urgent treatment visits was operationalized using the question "during the past 12 months, how many times did you see a doctor or other health professional for urgent treatment of worsening asthma symptoms or for an asthma episode or attack?' Both the number of ED visits and urgent care visits were categorized into dichotomous variables labeled as "no visits" and "any visits", and excluded "don't know/not sure" and/or "refused to answer".

\section{Assessment of independent variables}

Smoking status was operationalized by two separate questions. The first question asked "have you smoked at least 100 
Table 1. Sociodemographic characteristics of asthmatic adults in the 2011 Asthma Call-Back Survey by smoking status.

\begin{tabular}{|c|c|c|c|c|}
\hline & $\begin{array}{c}\text { Never smokers } \\
(N=6082) \\
{[n(\text { Weighted \%)] }}\end{array}$ & $\begin{array}{l}\text { Former smokers } \\
\quad(N=4176) \\
{[n(\text { Weighted \%)] }}\end{array}$ & $\begin{array}{l}\text { Current smokers } \\
\quad(N=2045) \\
{[n(\text { Weighted \%)] }}\end{array}$ & $p$ Value $^{\mathrm{a}}$ \\
\hline 18-48 years old & $1792(63.02)$ & $550(37.83)$ & $675(59.97)$ & \\
\hline 49-59 years old & $1552(17.40)$ & $943(22.56)$ & $716(24.79)$ & \\
\hline $60-68$ years old & $1312(10.57)$ & $1252(20.02)$ & $428(10.26)$ & \\
\hline 69 years or older & $1397(9.01)$ & $1419(19.59)$ & $215(4.98)$ & \\
\hline Female & $4712(64.40)$ & $2865(60.57)$ & $1516(60.39)$ & \\
\hline Body mass index $\left(\mathrm{kg} / \mathrm{m}^{2}\right)$ & & & & 0.001 \\
\hline Underweight/normal & $1503(29.71)$ & 939 (23.78) & $622(34.57)$ & \\
\hline Overweight & $1791(30.79)$ & $1278(27.49)$ & $598(29.18)$ & \\
\hline Obese & $2488(39.51)$ & $1786(48.73)$ & $768(36.25)$ & \\
\hline Racelethnicity & & & & $<0.0001$ \\
\hline$<\$ 25000$ & $1688(29.98)$ & $1542(36.25)$ & $1176(51.04)$ & \\
\hline$\$ 25000$ to $<\$ 50000$ & $1357(18.14)$ & $989(23.84)$ & $396(22.43)$ & \\
\hline$\geq \$ 50000$ & $2358(39.76)$ & $1249(30.58)$ & $253(12.06)$ & \\
\hline Don’t’ Know & $679(12.11)$ & $396(9.34)$ & $220(14.47)$ & \\
\hline Education level & & & & $<0.0001$ \\
\hline Grade 8 or less & $431(10.55)$ & $428(14.15)$ & $380(23.83)$ & \\
\hline High school & $1376(21.29)$ & $1200(27.38)$ & $748(36.80)$ & \\
\hline College & 4267 (68.16) & $2542(58.47)$ & $914(39.37)$ & \\
\hline Health coverage & & & & $<0.0001$ \\
\hline Yes & $5625(89.99)$ & $3930(91.05)$ & $1684(77.01)$ & \\
\hline No & $441(10.01)$ & $244(8.95)$ & 357 (22.99) & \\
\hline Physical Activity in the past 30 days & & & & $<0.0001$ \\
\hline Yes & $4303(76.72)$ & $2747(69.03)$ & $1106(58.31)$ & \\
\hline
\end{tabular}

$\mathrm{ED}=$ Emergency Department.

a $p$ values were calculated by the Pearson's Chi-square test.

cigarettes in your entire life?" to which adults' responded with "yes", "no", “don't know/not sure", or "refused to answer'. The second question asked "do you now smoke cigarettes every day, some days or not at all?" Adults chose one of three options to identify their frequency of smoking: "every day", "some days" or "not at all". The exposure variable was grouped into three smoking categories: "never smokers", "former smokers", and "current smokers" and excluded data from those who answered 'don't know/not sure" and/or "refused to answer".

Potential confounders of the association between ED visits and smoking among asthmatic patients included demographics and socioeconomic variables (Table 1). Based on the prior literature, we included relevant individual characteristics (i.e. age, sex, body mass index and race/ethnicity) [24-33], socioeconomic variables (i.e. household income, health coverage status and education level) and other related variables (i.e. physical activity in the past 30 days) in the analyses $[27,34,35]$.

Age was categorized into four discrete intervals (18-48, 49-59, 60-68 and 69 years or older). Body mass index $\left(\mathrm{kg} / \mathrm{m}^{2}\right)$ was categorized as underweight $(12.00 \leq \mathrm{BMI}<$ $18.50)$, normal weight $(18.50 \leq \mathrm{BMI}<25.00)$, overweight $(25.00 \leq \mathrm{BMI}<30.00)$ and obese $(30.00 \leq \mathrm{BMI}<99.99)$. Race was categorized into four separate groups White, Black, Hispanic or Other. The 'Other' category included Asian, Native Hawaiian or other Pacific Islander, American Indian or Alaskan Native, Multiracial and other race. Household income was determined by respondents' selfreported annual income from all sources and divided into four discrete intervals ("<\$25000", " $\$ 25000 \leq \$ 50000 "$, " $\geq \$ 50000 "$ and "Don't Know"). Education was categorized as "grade eight or less", "high school" and "college". Health coverage was determined by whether respondents were covered by any kind of health care coverage, including health insurance, prepaid plans such as HMOs or government plans such as Medicare or an Indian Health Service. Physical activity was measured as self-reported participation in any physical activity or exercise during the past 30 days, other than their regular job. Physical activity was assessed by the following question "during the past month, other than your regular job, did you participate in any physical activities or 
Table 2. Sociodemographic characteristics of asthmatic adults in the 2011 Asthma Call-Back Survey by emergency treatment.

\begin{tabular}{|c|c|c|c|c|}
\hline & $\begin{array}{c}\text { Any emergency } \\
\text { department visits for } \\
\text { asthma in the past } 12 \text { months } \\
(N=1595 \text { of } 12303) \\
[n \text { (Weighted } \%)]\end{array}$ & $p$ Value $^{\mathrm{a}}$ & $\begin{array}{l}\text { Any urgent treatment } \\
\text { visits for asthma in the } \\
\text { past } 12 \text { months } \\
(N=3039 \text { of } 12181) \\
{[n(\text { Weighted \%)] }}\end{array}$ & $p$ Value $^{\mathrm{a}}$ \\
\hline Smoking Status & & 0.000 & & 0.009 \\
\hline Never smokers & $695(11.27)$ & & $1446(21.11)$ & \\
\hline Former smokers & $517(13.90)$ & & 992 (26.18) & \\
\hline Current smokers & $380(18.72)$ & & $596(27.18)$ & \\
\hline Age & & $<0.0001$ & & $<0.0001$ \\
\hline $18-48$ years old & $433(12.72)$ & & $724(21.41)$ & \\
\hline 49-59 years old & $490(18.70)$ & & $906(29.52)$ & \\
\hline $60-68$ years old & $358(12.84)$ & & $746(25.13)$ & \\
\hline 69 years or older & $310(9.19)$ & & $654(22.96)$ & \\
\hline Sex & & $<0.0001$ & & $<0.0001$ \\
\hline Male & $308(9.58)$ & & $585(17.96)$ & \\
\hline Female & $1287(15.92)$ & & $2454(27.16)$ & \\
\hline Body mass index $\left(\mathrm{kg} / \mathrm{m}^{2}\right)$ & & 0.000 & & 0.027 \\
\hline Underweight & $25(7.91)$ & & $35(27.30)$ & \\
\hline Normal Weight & $319(10.19)$ & & $635(20.11)$ & \\
\hline Overweight & $403(12.67)$ & & $818(23.04)$ & \\
\hline Obese & $770(16.48)$ & & $1424(26.81)$ & \\
\hline Race/ethnicity & & 0.094 & & 0.061 \\
\hline White & 1088 (12.49) & & $2212(22.75)$ & \\
\hline Black & 207 (17.93) & & $338(30.88)$ & \\
\hline Hispanic & $157(13.50)$ & & $241(22.10)$ & \\
\hline Other & $135(16.17)$ & & $227(24.12)$ & \\
\hline Household income & & 0.000 & & 0.002 \\
\hline$<\$ 25000$ & $780(17.31)$ & & $1345(28.05)$ & \\
\hline$\$ 25000$ to $<\$ 50000$ & $307(12.97)$ & & $590(21.24)$ & \\
\hline$\geq \$ 50000$ & $340(9.44)$ & & $805(19.87)$ & \\
\hline Don’t know & $168(13.95)$ & & $299(24.88)$ & \\
\hline Education level & & $<0.0001$ & & 0.002 \\
\hline Grade 8 or less & $256(19.84)$ & & $402(30.83)$ & \\
\hline High school & $461(15.63)$ & & $825(25.52)$ & \\
\hline College & $876(11.12)$ & & $1809(21.26)$ & \\
\hline Health coverage & & 0.127 & & 0.019 \\
\hline Yes & $1442(13.13)$ & & $2815(24.61)$ & \\
\hline No & $151(16.69)$ & & $221(17.85)$ & \\
\hline Physical activity in the past 30 days & & 0.026 & & 0.009 \\
\hline Yes & $939(12.58)$ & & $1887(22.30)$ & \\
\hline No & $651(15.81)$ & & $1147(27.09)$ & \\
\hline
\end{tabular}

${ }^{a} p$ values were calculated by the Pearson's Chi-square test.

exercises such as running, calisthenics, golf, gardening or walking for exercise?"

\section{Analysis}

All statistical analyses were performed using SAS statistical software version 9.3 (SAS Institute Inc., Cary, NC) [36]. Bivariate analyses were conducted to examine relationships between demographic characteristics, smoking status (i.e. never smokers, former smokers and current smokers) and ED and urgent treatment visits using Pearson chi-squared tests. All $p$ values are two-sided, with $p<0.05$ considered statistically significant. Separate models were run for ED visits and for urgent treatment visits.

The BRFSS and ACBS weighting process included design weighting and iterative proportional fitting. All data were analyzed using statements of stratification, clustering and sample weight to account for the complex sampling design of survey data. Weighted data were used to estimate population parameters and account for non-response and non-coverage at both the BRFSS and ACBS interview. Both unweighted frequency $(\mathrm{N})$ and weighted percentages are reported in Table 1. Simple logistic regression was used to determine crude odds ratios. The multivariable logistic regression model adjusted for all potential confounders. Both crude and adjusted odds ratios are reported in Table 2. We calculated the attributable risk percent and population attributable risk percent using the adjusted odds ratio for current and former smokers and the weighted prevalence of current and former smoking. The estimate of population attributable risk percent is calculated as $100 *\left[P_{\mathrm{x}} *(\mathrm{OR}-1)\right] / 1+\left[P_{\mathrm{x}} *(\mathrm{OR}-1)\right]$ [37]. Finally, we conducted sensitivity analyses by running all multivariable logistic regression models when restricting the sample to participants aged $18-48$ years.

\section{Results}

Asthmatic adults were predominantly female (62.5\%), white (68.17\%) and had health insurance (87.41\%). In this study population, over half $(52.9 \%)$ were never smokers, $25.3 \%$ former smokers and $21.8 \%$ current smokers. Never smokers tended to have higher income, higher education and were 
Table 3. Unadjusted and adjusted odds of emergency care visits among asthmatic adults in the 2011 ACBS.

\begin{tabular}{|c|c|c|c|c|}
\hline & \multicolumn{2}{|c|}{$\begin{array}{c}\text { Any emergency department } \\
\text { visits for asthma in the } \\
\text { past } 12 \text { months }^{\mathrm{a}}(N=1595 \text { of } 12303)\end{array}$} & \multicolumn{2}{|c|}{$\begin{array}{l}\text { Any urgent treatment visits } \\
\text { for asthma in the } \\
\text { past } 12 \text { months }^{\mathrm{a}}(N=3039 \text { of } 12181)\end{array}$} \\
\hline & Crude OR $(95 \% \mathrm{CI})$ & Adjusted OR $(95 \% \mathrm{CI})^{\mathrm{b}}$ & Crude OR $(95 \% \mathrm{CI})$ & Adjusted OR $(95 \% \mathrm{CI})^{\mathrm{b}}$ \\
\hline \multicolumn{5}{|l|}{ Smoking status } \\
\hline Never smokers & REF & REF & REF & REF \\
\hline Former smokers & $1.27(0.96,1.69)$ & $1.30(0.97,1.74)$ & $1.33(1.06,1.66)$ & $1.28(0.99,1.65)$ \\
\hline
\end{tabular}

Both crude and adjusted odds ratios were weighted using survey logistic and ACBS weighting variables (_psu, ststr, landwt_f).

${ }^{\mathrm{a} C}$ Confidence intervals calculated by the Wald test.

${ }^{\mathrm{b}}$ Adjusted odds ratios included all sociodemographic variables (smoking status, age, sex, BMI, race/ethnicity, income, education, health coverage and physical activity in the past 30 days).

more likely to have exercised in the past 30 days. Former smokers were more likely to be white, tended to be older and have a higher BMI. Current smokers tended to be younger, have lower income, have less education and were less likely to have health coverage or have exercised in the past 30 days (Table 1).

Table 2 shows the distribution of demographic characteristics in this asthmatic population by emergency care visits (ED visits and urgent treatment visits). Asthmatic females $(15.9 \%)$ were more likely than males $(9.5 \%)$ to visit the ED; also females were more likely to visit a health professional for an urgent treatment visit (27.1\% versus $17.9 \%)$. Asthmatic adults, who were obese, were more likely to visit the ED or a health professional for an urgent treatment visit. Asthmatic adults without health coverage were more likely to visit the $\mathrm{ED}$; however, asthmatic adults with health coverage were more likely to visit their doctor for urgent treatment.

In the unadjusted model (Table 3), among asthmatic adults, former smokers had 1.27 (95\% CI: 0.96, 1.69) times the odds of having visited the ED as compared to never smokers during the past 12 months while current smokers had 1.82 (95\% CI: $1.36,2.42)$ times the odds of having visited the ED compared to those who have never smoked. Furthermore, former smokers had 1.33 (95\% CI: 1.06, 1.66) times the odds and current smokers had 1.40 (95\% CI: 1.08, 1.80) times the odds of visiting a doctor or other health professional for urgent treatment of worsening asthma symptoms during the past 12 months compared to never smokers.

In the adjusted models, most associations were attenuated but remained significant (Table 3). Adjusting for all relevant confounders, former smokers had 1.30 (95\% CI: 0.97, 1.74) times the odds and current smokers had 1.46 (95\% CI: 1.05 , 2.03) times the odds of visiting the ED during the past 12 months as compared to never smokers. In addition, former smokers had 1.28 (95\% CI: 0.99, 1.65) times the odds and current smokers had $1.29(0.96,1.73)$ times the odds of visiting a doctor or other health professional for urgent treatment of worsening asthma symptoms during the past 12 months.

Among adult asthmatic current smokers, $32 \%$ of ED visits and $23 \%$ of urgent treatment visits can be attributed to their current smoking. Among adult asthmatic former smokers, $23 \%$ of ED visits and $22 \%$ of urgent treatment visits can be attributed to their former smoking. Among the population of adult asthmatics, the percentage of ED visits and urgent treatment visits that would not occur if current cigarette smoking were eliminated was 9 and $6 \%$, respectively. An estimated $7 \%$ of ED visits and $7 \%$ of urgent treatment visits can be attributed to former smoking.

\section{Discussion}

Among asthmatic adults, current smokers were significantly more likely to have an emergency care visit and similarly, among former smokers there was an elevated although nonsignificant increase in likelihood to have an emergency care visit. More specifically, current smokers had significantly higher odds of an ED visit and significantly higher odds of making an urgent treatment visit to their health professional compared to never smokers when adjusting for confounders.

Previous studies have indicated current smokers report increased asthma attacks and asthma-related symptoms during the month than those who do not smoke [6,8,38-40]. The elimination of smoking among asthmatics will likely reduce ED visits and urgent treatment visits among asthmatic adults and therefore healthcare spending. For example, Kent et al. found that admissions to the ED due to acute pulmonary illness decreased significantly following the implementation of a smoking ban, from 439 admissions per 100000 population per year in the 2 years preceding to the ban to 396 admissions per 100000 population per year in the 2 years succeeding the ban. The smoking ban contributed to a relative reduction of $15 \%$ in overall ED admissions with acute pulmonary disease [41]. Scientific evidence increasingly shows that tobacco smoking by individuals with asthma exacerbates the asthmatic condition by damaging cilia in the airways and allowing dust and mucus to accumulate in the airways triggering an asthma attack, which in turn may lead to emergency care visits $[5,6,8,38-40]$. If we assume a causal relationship between smoking and emergency care, our study findings suggest that eliminating smoking (both former and current smoking) among the population of asthmatic adults will reduce their ED visits by $16 \%$ and urgent treatment visits by $13 \%$.

Study findings provide new empirical evidence of the relationship between smoking status and both ED and urgent treatment visits among a nationally representative sample of asthmatic adults. With approximately 1.9 million ED visits for asthma in 2009 [15], understanding the association of smoking and emergency care visits in this population will have implications for patients and emergency care 
professionals. Lenhardt et al. [14] found that although adults with asthma exacerbations presented to the ED improved with treatment, there was continued decline of the adults' asthmatic condition after the ED visit. Exposure to tobacco smoke, likely linked to uncontrolled asthma, may increase asthma-related emergencies; therefore, to reduce the potential for costly emergency care services, this population should be targeted for smoking prevention, smoking cessation programs and chronic disease management education.

There were some limitations of this study. For example, inferences from these results were limited by the crosssectional nature of the data; thus reverse causality cannot be ruled out. In addition, information about both ED visits and urgent treatment visits referred to "the past 12 months" while the smoking status information asked "do you now smoke cigarettes?' Due to this slight difference in timeframe of each question, we were unable to ascertain smoking status exactly at the time of emergency care. We considered the issue of severity of disease; however, as the data were cross-sectional, it was impossible to discern whether the measures used to determine asthma severity such as medication use and asthmatic attacks were before or after the emergency care visits.

In order to calculate the attributable risk, certain assumptions were made. Odds ratios were assumed to approximate risk ratios though they are likely an overestimate and both current and former smoking was assumed to be causally related to emergency care visits. However, these attributable fractions may be underestimates because asthmatic adults who require emergency care visits have multiple visits annually, on average. In fact, those who visit the ED average 2.4 (95\% CI: 2.06, 2.77) visits per year and those who visit their doctor for urgent treatment of asthma average 2.7 (95\% CI: 2.44, 2.95) visits per year. Given the sample included asthmatic adults from a broad range of ages (e.g. 18 through 85 years) and that age may be associated with ED visits, we restricted our sample to those aged 18-48 years. Age groupings were based on rough quartile distributions. Results showed associations to be similar but slightly higher than when conducted among the whole sample. According to the National Center for Health Statistics, females had higher asthma prevalence than males (9.2\% compared with $7.0 \%)$ for the period 2008-2010. Our asthmatic adult sample indicates there are 1.6 times as many females as males who have asthma, which is fairly consistent with these estimates [42].

The median survey response rate for the 2011 BRFSS was $52.9 \%$ and the response rate of the 2011 ACBS was $93.1 \%$ $[20,21]$. Although the BRFSS is limited by low response rates, the survey is considered one of the few available large, nationally representative health surveys. The BRFSS data are timely and the data are available within 6 months from end of the calendar year of data collection. For those who participated in the ACBS, the response rate was very high and the ACBS was used specifically to address asthma needs. A significant limitation of this study is that the ACBS was based on self-reported responses and participants may be prone to social desirability bias and recall bias. Potential residual confounding may have existed from other comorbidities.

The validity of self-reported asthma status in the BRFSS is unknown. According to a 1993 review of asthma questionnaires, the sensitivity and specificity of self-reported asthma when compared to a clinical diagnosis of asthma has been reported to be anywhere between $48-100 \%$ (sensitivity) and $78-100 \%$ (specificity) [43]. The BRFSS questions ask whether respondents have been told by a health professional they have asthma; however, it is possible that either the physician's diagnosis or the respondent's recall of that diagnosis might be inaccurate. Using a self-reported asthma measure may lead to a sample where many true asthmatic patients are not included or patients with other lung conditions are included. The question we proposed to examine is whether asthmatic adults who smoke have more frequent ED or urgent care visits than those who do not smoke. Since sensitivity is likely lower than specificity, we may have missed some of the asthmatics that were not asked to participate in the ACBS. However, the question is still relevant for those who recall being told by a health care provider that they had asthma and for those who still classify themselves as "current asthmatics". In addition, even though self-reported surveys have limitations, one study done by the Minnesota Department of Health demonstrated a good correlation between a positive answer and the presence of an asthma diagnosis in the medical record [44]. The BRFSS also remains the largest telephone survey in the world and a comprehensive source of state-level surveillance data for asthma and other chronic conditions [45].

Despite these limitations, this study included a large sample of asthmatic adults and was the first examination of this study question, to the best of our knowledge, among the US nationally representative sample. Study findings provided new empirical evidence on the relationship between smoking status and emergency care visits generalizable to asthmatic adults in the US.

Results suggest a health policy of increasing asthma management education, smoking cessation strategies and smoking prevention techniques may be effective and result in better asthma control and management. As a key site for care, both EDs and physician offices may serve as a prime location to address and implement smoking interventions. An intervention by healthcare professionals - by providing advice, counseling and pharmacotherapy - may improve this population's chance of quitting smoking. Moreover, additional research should focus on a better understanding of how altering smoking behavior can help improve asthma management and prevent asthma exacerbations. In our study, we calculated absolute measures of association as a way to estimate the potential public health impact if smoking was eliminated among asthmatics and the potential burden in this population if they do not quit smoking. The public health impact measurements only hold if smoking is causally related to emergency care visits among asthmatics. Both the ED and physician offices may want to consider offering cessation services within their site or referring patients to smoking cessation programs in the area. Evidence-based chronic disease self-management programs have shown improvement in the management of chronic disease and these types of programs could help patients change their smoking behavior to lower their risks for exacerbations of chronic illness and thereby avoid emergency care visits and future hospitalizations [46,47]. 


\section{Conclusions/key findings}

Although there are many tobacco control laws and policies at both the federal and state level, a more rigorous effort of smoking prevention and smoking cessation should be directed at this asthmatic population specifically among both current and former smokers. Smoking cessation and smoking prevention has the potential to improve pulmonary function in asthmatic patients, eliminate more than $10 \%$ of emergency care usage in this population assuming a causal relationship between smoking and emergency care, and prevent unnecessary health care costs.

\section{Acknowledgements}

Sophie A. Khokhawalla conceived the idea for the manuscript and conducted statistical data analyses. Annie Gjelsvik helped develop the theme and idea of the manuscript. Deborah N. Pearlman and Samantha R. Rosenthal helped develop the conceptual ideas and framework for the manuscript. Samantha R. Rosenthal and Elizabeth W. Triche helped conduct the statistical data analysis and contributed to writing the manuscript. Elizabeth W. Triche supervised the manuscript writing and data analysis. All authors read, edited and approved the final version of the manuscript.

\section{Declaration of interest}

The authors report no conflicts of interest.

\section{References}

1. U.S. Department of Health and Human Services. The Health Consequences of Smoking - 50 Years of Progress: a Report of the Surgeon General. Atlanta, GA: U.S. Department of Health and Human Services, Centers for Disease Control and Prevention, National Center for Chronic Disease Prevention and Health Promotion, Office on Smoking and Health; 2014.

2. Bernstein SL. The clinical impact of health behaviors on emergency department visits. Acad Emerg Med 2009;16:1054-1059.

3. Bock BC, Jennings E, Becker BM, Partridge R, Niaura RS. Characteristics and predictors of readiness to quit among emergency medical patients presenting with respiratory symptoms. Int J Emerg Med 2011;4:24.

4. Silverman RA, Boudreaux ED, Woodruff PG, Clark S, Camargo Jr CA,. Cigarette smoking among asthmatic adults presenting to 64 emergency departments. Chest 2003;123:1472-1479.

5. Thomson NC, Chaudhuri R, Livingston E. Asthma and cigarette smoking. Eur Respir J 2004;24:822-833.

6. Stapleton M, Howard-Thompson A, George C, Hoover RM, Self TH. Smoking and asthma. J Am Board Fam Med 2011;24:313-322.

7. Smith DH, Malone DC, Lawson KA, Okamoto LJ, Battista C, Saunders WB. A national estimate of the economic costs of asthma. Am J Respir Crit Care Med 1997;156:787-793.

8. Patel SN, Tsai CL, Boudreaux ED, Kilgannon JH, Sullivan AF, Blumenthal D, Camargo Jr CA. Multicenter study of cigarette smoking among patients presenting to the emergency department with acute asthma. Ann Allergy Asthma Immunol 2009;103: 121-127.

9. National Center for Health Statistics. Health, United States, 2012. With Special Feature on Emergency Care. Hyattsville, MD: National Center for Health Statistics; 2013.

10. Centers for Disease Control and Prevention. National surveillance of asthma: United States, 2001-2010. 2012. Available at: http:// www. cdc.gov/nchs/data/series/sr_03/sr03_035.pdf [last accessed 6 June 2014].

11. Barnett SB, Nurmagambetov TA. Costs of asthma in the United States: 2002-2007. J Allergy Clin Immunol 2011;127:145-152.

12. American Lung Association. Trends in asthma morbidity and mortality. 2012. Available at: http://www.lung.org/finding-cures/ our-research/trend-reports/asthma-trend-report.pdf [last accessed 6 June 2014].

13. Cowie RL, Underwood MF, Revitt SG, Field SK. Predicting emergency department utilization in adults with asthma: a cohort study. J Asthma 2001;38:179-184.

14. Lenhardt RO, Catrambone CD, Walter J, McDermott MF, Weiss $\mathrm{KB}$. The asthma emergency department visit: treating a crisis in the midst of uncontrolled disease. Ann Allergy Asthma Immunology 2008; 100:237-243.

15. Centers for Disease Control and Prevention. Asthma's Impact on the Nation data from the CDC National Asthma Control Program. Available at http://www.cdc.gov/asthma/impacts_nation/ asthmafactsheet.pdf [last accessed 7 August 2014].

16. Centers for Disease Control and Prevention. Overview: Behavioral Risk Factor Surveillance Survey 2011. Available at http:// www.cdc.gov/brfss/annual_data/2011/overview_11.pdf [last accessed 15 Feb 2014].

17. Centers for Disease Control and Prevention. Behavioral risk factor surveillance system survey data. Atlanta, GA: U.S. Department of Health and Human Services; 2011.

18. Centers for Disease Control and Prevention. Behavioral risk factor surveillance system survey questionnaire. Atlanta, GA: U.S. Department of Health and Human Services; 2011.

19. National Asthma Control Program. 2011 Behavioral Risk Factor Surveillance Asthma Call-back Survey History and Analysis Guidance. Available at http://www.cdc.gov/BRfSS/acbs/2011/ documentations/ACBS_2011.pdf [last accessed 15 Feb 2014].

20. Centers for Disease Control and Prevention. Behavioral risk factor surveillance system 2011 summary data quality report. Available at http://www.cdc.gov/brfss/pdf/2011_summary_data_quality_report.pdf [last accessed 18 Oct 2014].

21. Centers for Disease Control and Prevention. Behavioral risk factor surveillance system 2011 asthma call back survey summary data quality report. Available at http://www.cdc.gov/brfss/acbs/2011/ documentations/SDQReportACBS_11.pdf [last accessed 18 Oct 2014].

22. The American Association for Public Opinion Research. Standard definition of case codes and outcome rates for surveys. 7th ed. Deerfield, IL:AAPOR; 2011. Available from http://www.aapor.org/ Standard_Definitions2.htm.

23. Centers for Disease Control and Prevention. Asthma call-back survey data. Atlanta, GA: U.S. Department of Health and Human Services; 2011.

24. Eisner MD, Iribarren $\mathrm{C}$. The influence of cigarette smoking on adult asthma outcomes. Nicotine Tobacco Res 2007;9:53-56.

25. Eisner MD, Katz PP, Yelin EH, Shiboski SC, Blanc PD. Risk factors for hospitalization among adults with asthma: the influence of sociodemographic factors and asthma severity. Respir Res 2001; 2:53-60.

26. Carr W, Zeitel L, Weiss K. Variations in asthma hospitalizations and deaths in New York City. Am J Public Health 1992;82:59-65.

27. Ray NF, Thamer M, Fadillioglu B, Gergen PJ. Race, income, urbanicity, and asthma hospitalization in California: a small area analysis. Chest 1998;113:1277-1284.

28. Gottlieb DJ, Beiser AS, O'Connor GT. Poverty, race, and medication use are correlates of asthma hospitalization rates. A small area analysis in Boston. Chest 1995;108:28-35.

29. De Palo VA, Mayo PH, Friedman P, Rosen MJ. Demographic influences on asthma hospital admission rates in New York City. Chest 1994;106:447-451.

30. Skobeloff EM, Spivey WH, St. Clair SS, Schoffstall JM. The influence of age and sex on asthma admissions. JAMA 1992;268: $3437-3440$.

31. Osborne ML, Vollmer WM, Linton KL, Buist AS. Characteristics of patients with asthma within a large HMO: a comparison by age and gender. Am J Respir Crit Care Med 1998;157:123-8.

32. Zoratti EM, Havstad S, Rodriguez J, Robens-Paradise Y, Lafata JE, McCarthy B. Health service use by African Americans and Caucasians with asthma in a managed care setting. Am J Respir Crit Care Med 1998;158:371-377.

33. Schatz M, Clark S, Camargo Jr CA,. Sex differences in the presentation and course of asthma hospitalizations. Chest 2006;129: $50-55$.

34. Haas JS, Cleary PD, Guadagnoli E, Fanta C, Epstein AM. The impact of socioeconomic status on the intensity of ambulatory 
treatment and health outcomes after hospital discharge for adults with asthma. J Gen Intern Med 1994;9:121-126.

35. Komaromy M, Lurie N, Osmond D, Vranizan K, Keane D, Bindman AB. Physician practice style and rates of hospitalization for chronic medical conditions. Med Care 1996;34:594-609.

36. SAS Software [computer program]. Version 9.3. Cary, NC: SAS Institute Inc; 2011.

37. Levin ML. The occurrence of lung cancer in man. Acta Unio Int Contra Cancrum 1953;9:531-541.

38. Strine TW, Balluz LS, Ford ES. The associations between smoking, physical inactivity, obesity, and asthma severity in the general US population. J Asthma 2007;44:651-658.

39. Schatz M, Zeiger RS, Vollmer WM, Mosen D, Cook EF. Determinants of future long-term asthma control. J Allergy Clin Immunol 2006;118:1048-1053.

40. Chaudhuri R, McSharry C, McCoard A, Livingston E, Hothersall E, Spears M, Lafferty J, Thomson NC. Role of symptoms and lung function in determining asthma control in smokers with asthma. Allergy 2008;63:132-135.

41. Kent BD, Sulaiman I, Nicholson TT, Lane SJ, Moloney ED. Acute pulmonary admissions following implementation of a national workplace smoking ban. Chest 2012;142:673-679.
42. Akinbami LJ, Moorman JE, Bailey C, Zahran HS, King M, Johnson CA, Liu X. Trends in asthma prevalence, health care use, and mortality in the United States, 2001-2010. NCHS data brief, no 94. Hyattsville, MD: National Center for Health Statistics; 2012.

43. Toren K, Brisman J, Jarvholm B. Asthma and asthma-like symptoms in adults assessed by questionnaires. A literature review. Chest 1993;104:600-608.

44. Minnesota Department of Health. Childhood Respiratory Health Feasibility Study: Inver Grove Heights and Eagan, Minnesota. 1991. http://www.health.state.mn.us/divs/hpcd/cdee/asthma/documents/asthmaepireport08.pdf [last accessed 20 Oct 2014].

45. Centers for Disease Control and Prevention. About the Behavioral Risk Factor Surveillance System (BRFSS). Atlanta, GA: U.S. Department of Health and Human Services; 2013.

46. Lorig KR, Sobel DS, Ritter PL, Laurent D, Hobbs M. Effect of a self-management program on patients with chronic disease. Eff Clin Pract 2001;4:256-262.

47. Lorig KR, Sobel DS, Stewart AL, Brown Jr BW,, Bandura A, Ritter P, Gonzalez VM, et al. Evidence suggesting that a chronic disease self-management program can improve health status while reducing hospitalization: a randomized trial. Med Care 1999;37: $5-14$. 